\title{
Diversity of respiratory impedance based on quantitative computed tomography in patients with COPD
}

This article was published in the following Dove Press journal: International Journal of COPD

\author{
Yosuke Wada' \\ Yoshiaki Kitaguchi' \\ Masanori Yasuo' \\ Fumika Ueno' \\ Satoshi Kawakami² \\ Kiyoyasu Fukushima ${ }^{3}$ \\ Keisaku Fujimoto ${ }^{4}$ \\ Masayuki Hanaoka' \\ 'First Department of Internal \\ Medicine, Shinshu University School \\ of Medicine, Matsumoto, Nagano, \\ Japan; ${ }^{2}$ Department of Radiology, \\ Shinshu University School of \\ Medicine, Matsumoto, Nagano, Japan; \\ ${ }^{3}$ Department of Respiratory Medicine, \\ Japanese Red Cross Nagasaki \\ Genbaku Isahaya Hospital, Isahaya, \\ Nagasaki, Japan; ${ }^{4}$ Departments of \\ Clinical Laboratory Sciences, Shinshu \\ University School of Health Sciences, \\ Matsumoto, Nagano, Japan
}

Correspondence: Yoshiaki Kitaguchi The First Department of Internal Medicine, Shinshu University School of Medicine, 3-I-I Asahi, Matsumoto 390-8621, Nagano, Japan Email kitaguti@shinshu-u.ac.jp
Introduction: This study was conducted in order to investigate the diversity of respiratory physiology, including the respiratory impedance and reversibility of airway obstruction, based on quantitative computed tomography (CT) in patients with COPD.

Patients and methods: Medical records of 174 stable COPD patients were retrospectively reviewed to obtain the patients' clinical data, including the pulmonary function and imaging data. According to the software-based quantification of the degree of emphysema and airway wall thickness, the patients were classified into the "normal by CT" phenotype, the airwaydominant phenotype, the emphysema-dominant phenotype, and the mixed phenotype. The pulmonary function, including the respiratory impedance evaluated by using the forced oscillation technique (FOT) and the reversibility of airway obstruction in response to inhaled short-acting $\beta_{2}$-agonists, was then compared among the four phenotypes.

Results: The respiratory system resistance at 5 and $20 \mathrm{~Hz}$ (R5 and R20) was significantly higher, and the respiratory system reactance at $5 \mathrm{~Hz}$ (X5) was significantly more negative in the airway-dominant and mixed phenotypes than in the other phenotypes. The within-breath changes of X5 ( $\triangle \mathrm{X} 5)$ were significantly greater in the mixed phenotype than in the "normal by CT" and emphysema-dominant phenotypes. The FOT parameters (R5, R20, and X5) were significantly correlated with indices of the degree of airway wall thickness and significantly but weakly correlated with the reversibility of airway obstruction. There was no significant correlation between the FOT parameters (R5, R20, and X5) and the degree of emphysema.

Conclusion: There is a diversity of respiratory physiology, including the respiratory impedance and reversibility of airway obstruction, based on quantitative CT in patients with COPD. The FOT measurements may reflect the degree of airway disease and aid in detecting airway remodeling in patients with COPD.

Keywords: FOT, respiratory impedance, MostGraph, AWT-Pi10

\section{Introduction}

COPD can be classified into various phenotypes morphologically based on the findings of chest computed tomography (CT) according to the presence of emphysema and/or the presence of airway wall thickness. ${ }^{1-5}$ The morphological phenotypes of COPD show distinct clinical characteristics and responsiveness to treatment with bronchodilators and inhaled corticosteroids. ${ }^{4,5}$ Recently, a software-based quantification of the degree of emphysema and airway wall thickness on chest CT, known as quantitative CT, is available and has been used increasingly. ${ }^{6-8}$

Forced oscillation technique (FOT) is a simple method for assessing the oscillatory flow resistance of the respiratory system and has provided important findings 
in respiratory physiology. ${ }^{9-11}$ FOT is theoretically sensitive to the peripheral airway function and is easy to administer because it is an effort-independent method of evaluating lung mechanics. ${ }^{12,13}$ The real part of impedance is called the respiratory system resistance (Rrs), whereas the imaginary part is called the respiratory system reactance (Xrs), which is supposed to reflect elastic and inertial properties of lungs. The FOT parameters of Rrs and Xrs are parameters of the airway caliber and of the elastic properties of the respiratory system, respectively, and they reflect the properties of both small and large airways. ${ }^{11}$ In patients with pulmonary obstructive diseases, the oscillatory flow resistance of the respiratory system tends to increase with the degree of airway obstruction, resulting in an increase in the Rrs and negative values in the Xrs. The Rrs increased, and the Xrs fell to a more negative level in patients with COPD and asthma in a severity-dependent fashion, regardless of respiratory phase. ${ }^{9,10,14} \mathrm{Xrs}$ is sensitive and specific to the presence of expiratory flow limitation in patients with COPD. ${ }^{15}$ The within-breath changes of the $\mathrm{Xrs}$ at $5 \mathrm{~Hz}(\Delta \mathrm{X} 5)$, which is an oscillatory parameter of difference in respiratory reactance between inspiratory and expiratory phases, were significantly higher in patients with COPD than in those with asthma and in control subjects. ${ }^{16,17}$

However, it is unclear whether values of the FOT parameters vary among patients with COPD or not, when they are classified by CT-based phenotype. We hypothesized that differences in morphological changes among phenotypes are associated with differences in pulmonary function, including the respiratory impedance and reversibility of airway obstruction. This study was conducted in order to investigate diversity of respiratory physiology, including the respiratory impedance and reversibility of airway obstruction, based on quantitative $\mathrm{CT}$ in patients with COPD.

\section{Patients and methods}

\section{Subjects}

Medical records of 174 stable COPD patients with forced expiratory volume in 1 second $\left(\mathrm{FEV}_{1}\right)$ /forced vital capacity (FVC) $<70 \%$ and $\mathrm{FEV}_{1}<80 \%$ of the predicted value after inhalation of short-acting $\beta_{2}$-agonists (moderate-tovery severe COPD) who were first seen at the outpatient clinic of Shinshu University Hospital from April 2012 to October 2016 were retrospectively reviewed to obtain the patients' clinical data, including the diagnosis, age, gender, body weight, body height, and smoking history. All patients underwent chest CT and pulmonary function tests, including respiratory impedance and reversibility of airway obstruction.
No patient had received treatment for COPD before the examinations. The diagnosis of COPD was based on the patients' clinical history and symptoms, including dyspnea on exertion and the pulmonary function characterized by persistent airflow obstruction $\left(\mathrm{FEV}_{1} / \mathrm{FVC}<70 \%\right.$ after inhalation of short-acting $\beta_{2}$-agonists), in accordance with the Global Initiative for Chronic Obstructive Lung Disease (GOLD) guidelines. ${ }^{18}$ All patients had a smoking history of $>10$ pack-years. No patients had a history of asthma.

This study was approved by the institutional research ethics committee of Shinshu University School of Medicine, and all patients gave their written informed consent to participate (the approval number: 3911).

\section{Pulmonary function tests}

Spirometry, measurements of the diffusion capacity of the lung for carbon monoxide (DLCO) and closing volume, and a global measure of ventilation heterogeneity (the slope of Phase III of the single breath nitrogen washout test [delta $\mathrm{N}_{2}$ ]) were performed by using a pulmonary function testing system (Chestac-8900 ${ }^{\circledR}$; Chest Co., Ltd., Tokyo, Japan). FEV 1 was measured before and 20 minutes after inhalation of shortacting $\beta_{2}$-agonists ( $200 \mu \mathrm{g}$ of salbutamol sulfate) by aerosol (metered-dose inhaler) with a spacer to evaluate the reversibility of airflow obstruction. The functional residual capacity was measured by using a body plethysmograph (Body Box; MGC Diagnostics, Ann Arbor, MI, USA), after which the patients immediately inspired to the total lung capacity (TLC) and expired maximally to the residual volume (RV).

The respiratory impedance was measured by using a commercially available multifrequency FOT device (MostGraph- $01^{\circledR}$; Chest Co., Ltd.) as previously reported, ${ }^{16,19,20}$ following the standard recommendations. ${ }^{21}$ We evaluated Rrs at $5 \mathrm{~Hz}$ (R5), Rrs at $20 \mathrm{~Hz}$ (R20), Xrs at $5 \mathrm{~Hz}$ (X5), resonant frequency (Fres), and low-frequency reactance area (ALX). The difference between the inspiratory and expiratory phases was calculated for each oscillatory parameter. These FOT measurements were performed prior to other pulmonary function tests.

\section{Evaluation of the degree of emphysema and airway wall thickness}

Chest CT was performed in the supine position at suspended full inspiration by using a 64-row multi-detector CT (LightSpeed VCT; GE Healthcare, Buckinghamshire, UK). The scanning parameters were as follows: collimation, $64 \times 0.625$ $\mathrm{mm}$; tube voltage, $120 \mathrm{kV}$; tube current, variable; rotation time, $0.4 \mathrm{~s}$. Images were reconstructed by using a standard 
reconstruction algorithm for the lung by using a slice thickness of $1.25 \mathrm{~mm}$. To evaluate the degree of emphysema, CT images were analyzed automatically by using an imageanalyzing software (INTAGE Station LungVision ${ }^{\circledR}$ Version 3.0; Cybernet, Inc., Tokyo, Japan) and as the percentage of low attenuation volume (LAV\%). The LAV\% was defined as percent lung tissue $\leq-950$ Hounsfield Unit (HU) on inspiratory $\mathrm{CT}$, as in previous studies. ${ }^{1-3}$ To evaluate the degree of airway wall thickness, CT images were analyzed by using an image-analyzing software (ZioCube ${ }^{\circledR}$; Ziosoft, Inc., Tokyo, Japan) and presented as a standardized measure for airway wall thickness (AWT-Pi10) and percentage of airway wall area (WA\%) as previously described. ${ }^{6,7,22}$ AWT-Pi10 is the standardized airway wall thickness at an internal perimeter of $10 \mathrm{~mm}$ and is calculated by using linear regression in which the square root of wall area of each measured segment is plotted against its internal perimeter to avoid potential bias issues surrounding different distribution of airway sizes among the subjects. ${ }^{6,7,22}$ All visible bronchial images up to the sixth generation (the segmental, subsegmental, and subsubsegmental bronchi on inspiratory $\mathrm{CT}$ ), which were cut in cross-section (short to long axis $>2: 3$ ), were identified in whole lung fields for each patient. Only segments with an internal perimeter of 6-20 mm were selected for the estimation of AWT-Pi10.22

\section{Classification of COPD into four phenotypes}

We defined the upper limits of "normal" for the CT measurements of LAV\% and AWT-Pi10 as the mean + 2 SD for these measurements in 20 non-COPD smokers as previously described. ${ }^{3,23}$ The upper limit of AWT-Pi10 was found to be 4.30 and that of LAV\% was $3.0 \%$. Based on these cutoff values, patients with COPD were classified into four phenotypes as follows: 1) normal by CT phenotype (NCT; low LAV\% and low AWT-Pi10), 2) airway-dominant phenotype (AD; low LAV\% and high AWT-Pi10), 3) emphysemadominant phenotype (ED; high LAV\% and low AWT-Pi10), and 4) mixed phenotype (high LAV\% and high AWT-Pi10) (Figure 1).

\section{Statistical analyses}

The values shown in the figures and tables represent the mean \pm standard error of the mean. The data distribution of the variables in various groups was first assessed by using Bartlett's test. If the data for the variables showed a normal distribution, they were compared using one-way analysis of variance, followed by multiple comparisons according to the Tukey-Kramer method. If the data for the variables did not show a normal distribution, the variables were compared by using the Kruskal-Wallis test, followed by multiple comparisons among groups with the nonparametric TukeyKramer method. Simple correlations between variables were examined by calculating Pearson correlation coefficients for parametric data and Spearman correlation coefficients for nonparametric data. All statistical analyses were performed by using a software StatFlex ${ }^{\circledR}$ Version 6.0 (Artech, Osaka, Japan). $p$-values of $<0.05$ were considered to indicate statistical significance in all the statistical analyses.

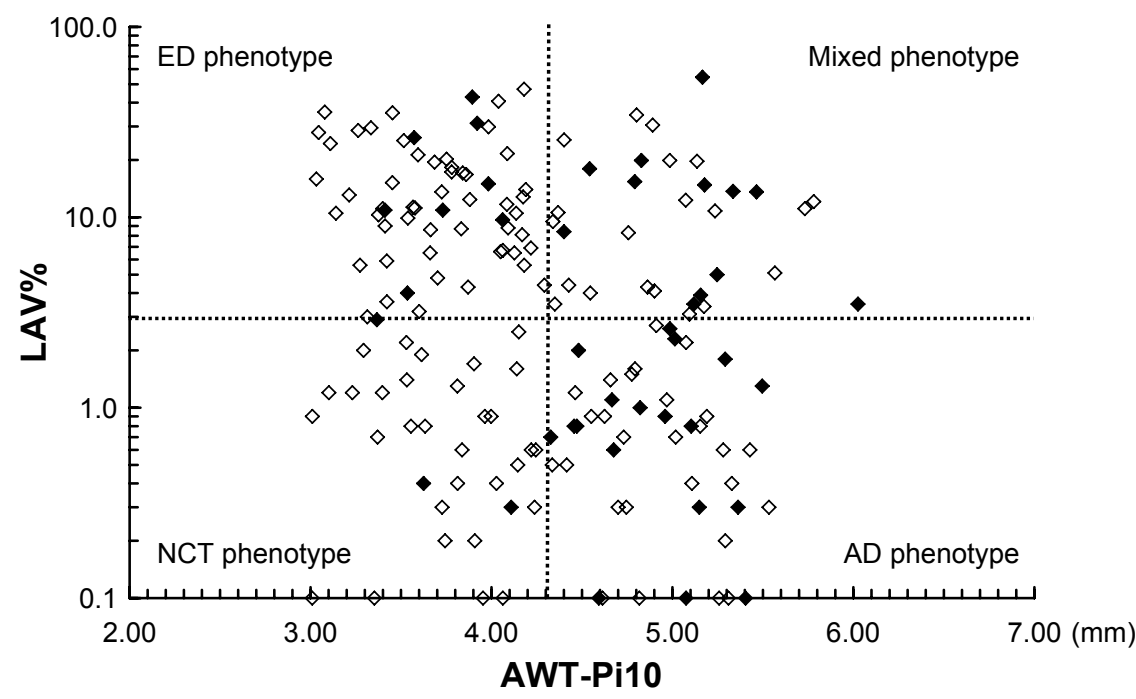

Figure I Correlation between AWT-Pil 0 and percentage of low attenuation volume (LAV\%) in I74 patients with COPD.

Notes: Bronchodilator response using $200 \mu \mathrm{g}$ salbutamol of FEV $\geq 200 \mathrm{~mL}$ and $12 \%$ from baseline values. $\diamond$ : bronchodilator response using $200 \mu \mathrm{g}$ salbutamol of FEV $<200 \mathrm{~mL}$ and I2\% from baseline values. Horizontal line shows mean $+2 \mathrm{SD}$ of LAV\% in the asymptomatic smokers. Vertical line shows mean $+2 \mathrm{SD}$ of AWT-Pil0 in the asymptomatic smokers.

Abbreviations: NCT, normal by computed tomography; AD, airway-dominant; ED, emphysema-dominant; FEV , forced expiratory volume in I second; AWT, airway wall thickness. 


\section{Results}

\section{Clinical characteristics and pulmonary function}

Figure 1 shows the correlation between AWT-Pi10 and LAV\%. The proportion of patients who showed the reversibility of airflow obstruction, defined as an increase in $\mathrm{FEV}_{1}$ by $>12 \%$ and $200 \mathrm{~mL}$ from baseline values in response to short-acting $\beta_{2}$-agonists, was significantly higher in the AD phenotype than in the NCT $(38.8 \%$ vs $11.1 \%, p<0.05)$ and ED phenotypes $(38.8 \%$ vs $13.8 \%, p<0.05)$. The proportion of those patients also tended to be higher in the mixed phenotype (35.5\%), but not statistically significant.

There were no significant differences in age, gender, or Brinkman index among the four phenotypes (Table 1). Body mass index was significantly lower in the ED phenotype than in the NCT and AD phenotypes. There was no significant difference in VC among the four phenotypes. FVC was significantly higher in the ED phenotype than in the other phenotypes. $\mathrm{FEV}_{1}$ was significantly lower in the mixed phenotype than in the other phenotypes. $\mathrm{FEV}_{1} / \mathrm{FVC}$ was significantly lower in the ED and mixed phenotypes than in the NCT and
AD phenotypes. RV and TLC were significantly higher in the ED and mixed phenotypes than in the other phenotypes. DLCO and DLCO/VA were significantly lower in the ED and mixed phenotypes than in the other phenotypes. Delta $\mathrm{N}_{2}$ was significantly higher in the ED phenotype and tended to be higher in the mixed phenotype than in NCT and AD phenotypes.

Figure 2 shows the reversibility of airflow obstruction in response to short-acting $\beta_{2}$-agonists, which was expressed by an increase in $\mathrm{FEV}_{1}$ from the baseline value. The increases in $\mathrm{FEV}_{1}$ and \% change in $\mathrm{FEV}_{1}$ were significantly greater in the AD phenotype than in the NCT and ED phenotypes.

\section{Respiratory impedance}

Regardless of respiratory phase, R5, R20, and ALX were significantly higher, and X5 was significantly more negative in the AD and mixed phenotypes than in the NCT and ED phenotypes (Table 2). $\Delta$ X5 was significantly greater in the mixed phenotype and tended to be greater in the AD phenotype than in the NCT and ED phenotypes. $\triangle \mathrm{ALX}$ was significantly more negative in the mixed phenotype and

Table I Clinical characteristics of patients with the NCT, AD, ED, and mixed phenotypes

\begin{tabular}{|c|c|c|c|c|}
\hline & $\begin{array}{l}\text { NCT } \\
\text { phenotype } \\
(n=36)\end{array}$ & $\begin{array}{l}\text { AD } \\
\text { phenotype } \\
(n=49)\end{array}$ & $\begin{array}{l}\text { ED } \\
\text { phenotype } \\
(n=58)\end{array}$ & $\begin{array}{l}\text { Mixed } \\
\text { phenotype } \\
(n=31)\end{array}$ \\
\hline Age, years & $71.3 \pm 1.5$ & $70.1 \pm 1.2$ & $71.6 \pm 0.9$ & $73.3 \pm 1.1$ \\
\hline \multicolumn{5}{|l|}{ Gender } \\
\hline Male, n (\%) & $36(100 \%)$ & 47 (95.9\%) & $56(96.6 \%)$ & $30(96.8 \%)$ \\
\hline Female, n (\%) & $0(0 \%)$ & $2(4.1 \%)$ & $2(3.4 \%)$ & I (3.2\%) \\
\hline Body mass index, $\mathrm{kg} / \mathrm{m}^{2}$ & $23.0 \pm 0.5$ & $23.6 \pm 0.5$ & $20.7 \pm 0.4^{* * . \$ \$}$ & $21.5 \pm 0.6^{\$}$ \\
\hline Brinkman index, pack-years & $58.7 \pm 5.6$ & $55.6 \pm 4.6$ & $59.8 \pm 2.9$ & $62.2 \pm 5.8$ \\
\hline \multicolumn{5}{|l|}{ Chest $\mathrm{CT}$ findings } \\
\hline AWT-Pil0 & $3.69 \pm 0.06$ & $4.94 \pm 0.05 * *$ & $3.75 \pm 0.05^{\$ \$}$ & $4.90 \pm 0.08 * *$, 抹 \\
\hline WA $\%, \%$ & $59.9 \pm 0.9$ & $73.8 \pm 0.8 * *$ & $61.3 \pm 0.8^{\$ \$}$ & $75.2 \pm 0.9 * *, \neq \neq$ \\
\hline LAV\%, \% & $1.04 \pm 0.15$ & $0.87 \pm 0.11$ & $16.29 \pm 1.43 * *, \$ \$$ & $12.36 \pm 1.88 * *, \$ \$$ \\
\hline \multicolumn{5}{|l|}{ Pulmonary function } \\
\hline VC, \% predicted & $88.4 I \pm 2.44$ & $90.00 \pm 1.68$ & $95.74 \pm 2.00$ & $92.82 \pm 2.87$ \\
\hline FVC, \% predicted & $85.36 \pm 2.42$ & $86.5 I \pm I .7 I$ & $95.40 \pm 2.29 * . \$$ & $86.31 \pm 3.28^{\ddagger}$ \\
\hline $\mathrm{FEV}_{1}, \%$ predicted & $65.76 \pm 2.10$ & $60.80 \pm 1.66$ & $58.60 \pm 1.95$ & $49.04 \pm 2.66 * * . \$ . \neq$ \\
\hline $\mathrm{FEV}_{1} / \mathrm{FVC}, \%$ & $61.71 \pm 0.79$ & $56.79 \pm 1.27$ & $49.23 \pm 1.29 * *, \$ \$$ & $45.40 \pm 1.98 * * \$ \$$ \\
\hline FRC, \% predicted & $92.21 \pm 2.52$ & $98.31 \pm 3.24$ & $108.22 \pm 3.40 * *$ & $107.97 \pm 3.44 * *$ \\
\hline RV, \% predicted & $138.59 \pm 4.32$ & $142.26 \pm 5.72$ & $162.93 \pm 6.78^{* . \$}$ & $168.67 \pm 6.17^{* * . \$ \$}$ \\
\hline TLC, \% predicted & $104.55 \pm 2.20$ & $106.79 \pm 2.03$ & $117.97 \pm 2.56 * * \$ \$$ & $116.73 \pm 2.61 * *, \$$ \\
\hline DLCO, \% predicted & $71.21 \pm 2.74$ & $76.50 \pm 2.88$ & $53.58 \pm 3.11 * * . \$ \$$ & $54.95 \pm 3.83 * * . \$ \$$ \\
\hline DLCO/VA, \% predicted & $94.28 \pm 3.31$ & $100.29 \pm 3.73$ & $63.16 \pm 2.81 * *, \$ \$$ & $67.65 \pm 4.58 * *, \$ \$$ \\
\hline delta $\mathrm{N}_{2}, \% \mathrm{~N}_{2} / \mathrm{L}$ & $2.99 \pm 0.31$ & $3.02 \pm 0.26$ & $4.31 \pm 0.33^{*} \$ \$$ & $4.34 \pm 0.76$ \\
\hline
\end{tabular}

Note: Values are presented as mean \pm standard error of the mean; ${ }^{* *} p<0.0$ I, ${ }^{*} p<0.05$ versus the NCT phenotype; ${ }^{\$ \$} p<0.0$ I, ${ }^{\$} p<0.05$ versus the AD phenotype; ${ }^{*} p<0.0$ I, ${ }^{\ddagger} p<0.05$ versus the ED phenotype.

Abbreviations: NCT, normal by computed tomography; AD, airway-dominant; ED, emphysema-dominant; AWT, airway wall thickness; WA\%, percentage of wall area; LAV\%, percentage of low-attenuation volume; VC, vital capacity; FVC, forced vital capacity; FEV , forced expiratory volume in I second; FRC, functional residual capacity; RV, residual volume; TLC, total lung capacity; DLCO, diffusing capacity of lung for carbon monoxide; DLCO/VA, diffusing capacity of lung for carbon monoxide/alveolar volume. 

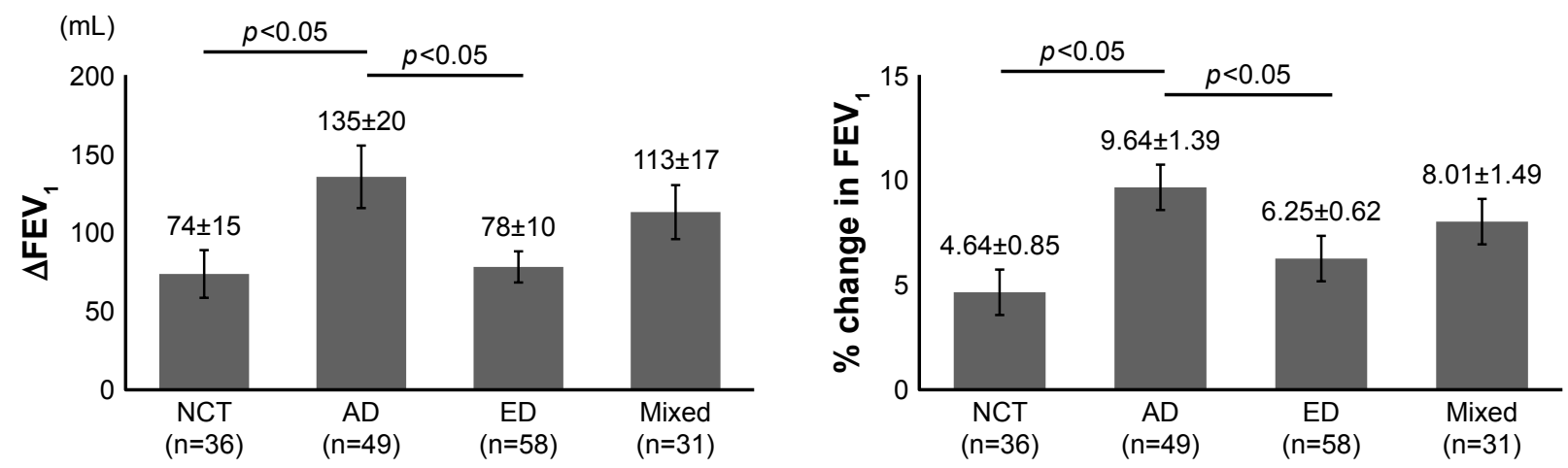

Figure 2 Response to short-acting $\beta_{2}$ agonists in patients with the NCT, AD, ED, and mixed phenotypes.

Note: Values are mean \pm standard error of the mean.

Abbreviations: NCT, normal by computed tomography; AD, airway-dominant; ED, emphysema-dominant; FEV $\mathrm{F}_{1}$, forced expiratory volume in I second.

tended to be more negative in the $\mathrm{AD}$ phenotype than in the NCT and ED phenotypes.

There were significant correlations between the FOT parameters (R5, R20, and X5) and indices of the degree of airway wall thickness (AWT-Pi10 and WA\%) (Table 3; Figure 3). There were significant but weak correlations between the FOT parameters (R5, R20, and X5) and the reversibility of airway obstruction (increases in $\mathrm{FEV}_{1}$ and \%

Table 2 Respiratory impedance in patients with the NCT, AD, ED, and mixed phenotypes

\begin{tabular}{|c|c|c|c|c|}
\hline & $\begin{array}{l}\text { NCT } \\
\text { phenotype } \\
(n=36)\end{array}$ & $\begin{array}{l}\text { AD } \\
\text { phenotype } \\
(n=49)\end{array}$ & $\begin{array}{l}\text { ED } \\
\text { phenotype } \\
(n=58)\end{array}$ & $\begin{array}{l}\text { Mixed } \\
\text { phenotype } \\
(n=31)\end{array}$ \\
\hline \multicolumn{5}{|l|}{ Whole breath } \\
\hline $\mathrm{R} 5\left(\mathrm{cmH}_{2} \mathrm{O} / \mathrm{L} / \mathrm{s}\right)$ & $2.87 \pm 0.20$ & $4.32 \pm 1.44 * *$ & $3.16 \pm 0.14^{\$ \$}$ & $4.15 \pm 0.18^{* *,+\neq}$ \\
\hline $\mathrm{R} 20\left(\mathrm{cmH}_{2} \mathrm{O} / \mathrm{L} / \mathrm{s}\right)$ & $2.31 \pm 0.14$ & $3.38 \pm 0.17 * *$ & $2.43 \pm 0.09^{\$ \$}$ & $3.14 \pm 0.75^{* *,+\ddagger}$ \\
\hline $\mathrm{R} 5-\mathrm{R} 20\left(\mathrm{cmH}_{2} \mathrm{O} / \mathrm{L} / \mathrm{s}\right)$ & $0.60 \pm 0.08$ & $0.94 \pm 0.10^{*}$ & $0.73 \pm 0.07$ & $\mathrm{I} .0 \mathrm{I} \pm 0.07^{* *}$ \\
\hline $\mathrm{X} 5\left(\mathrm{cmH}_{2} \mathrm{O} / \mathrm{L} / \mathrm{s}\right)$ & $-0.95 \pm 0.16$ & $-1.97 \pm 0.20 * *$ & $-1.12 \pm 0.13^{\$ \$}$ & $-2.12 \pm 0.26 * * ., \neq$ \\
\hline Fres $(\mathrm{Hz})$ & $11.37 \pm 0.79$ & $16.14 \pm 0.79 * *$ & $13.36 \pm 0.76$ & $17.90 \pm 0.97 * *, \ldots$ \\
\hline $\mathrm{ALX}\left(\mathrm{cmH}_{2} \mathrm{O} / \mathrm{L} / \mathrm{s} \mathrm{Hz}\right)$ & $6.08 \pm 1.42$ & $15.63 \pm 2.08 * *$ & $8.42 \pm 1.25^{\$}$ & $17.95 \pm 2.93 * *, \ldots$ \\
\hline \multicolumn{5}{|l|}{ Expiratory phase } \\
\hline $\mathrm{R} 5\left(\mathrm{cmH}_{2} \mathrm{O} / \mathrm{L} / \mathrm{s}\right)$ & $3.1 I \pm 0.23$ & $4.66 \pm 0.24 * *$ & $3.50 \pm 0.16^{\$ \$}$ & $4.5 I \pm 0.2 I^{* *,+\neq}$ \\
\hline $\mathrm{R} 20\left(\mathrm{cmH}_{2} \mathrm{O} / \mathrm{L} / \mathrm{s}\right)$ & $2.43 \pm 0.15$ & $3.5 \mathrm{I} \pm 0.20 * *$ & $2.60 \pm 0.11 \$ \$$ & $3.29 \pm 0.14^{* *, \pm \ddagger}$ \\
\hline $\mathrm{R} 5-\mathrm{R} 20\left(\mathrm{cmH}_{2} \mathrm{O} / \mathrm{L} / \mathrm{s}\right)$ & $0.60 \pm 0.10$ & $1.15 \pm 0.1 I^{* *}$ & $0.90 \pm 0.07$ & $1.22 \pm 0.10^{* *}$ \\
\hline $\mathrm{X} 5\left(\mathrm{cmH}_{2} \mathrm{O} / \mathrm{L} / \mathrm{s}\right)$ & $-1.12 \pm 0.22$ & $-2.63 \pm 0.32 * *$ & $-1.46 \pm 0.19 \$$ & $-2.93 \pm 0.42^{* *, \text { 扞 }}$ \\
\hline Fres $(\mathrm{Hz})$ & $12.24 \pm 0.94$ & $18.14 \pm 0.97 * *$ & $14.82 \pm 0.89$ & $20.32 \pm 1.22^{* *, \neq \ddagger}$ \\
\hline $\mathrm{ALX}\left(\mathrm{cmH}_{2} \mathrm{O} / \mathrm{L} / \mathrm{s} \mathrm{Hz}\right)$ & $7.78 \pm 1.99$ & $22.54 \pm 3.34 * *$ & $11.96 \pm 1.97$ & $26.91 \pm 5.01 * *, \neq$ \\
\hline \multicolumn{5}{|l|}{ Inspiratory phase } \\
\hline $\mathrm{R} 5\left(\mathrm{cmH}_{2} \mathrm{O} / \mathrm{L} / \mathrm{s}\right)$ & $2.62 \pm 0.18$ & $3.97 \pm 0.19 * *$ & $2.81 \pm 0.13^{\$ \$}$ & $3.77 \pm 0.17^{* *, \ddagger \ddagger}$ \\
\hline $\mathrm{R} 20\left(\mathrm{cmH}_{2} \mathrm{O} / \mathrm{L} / \mathrm{s}\right)$ & $2.19 \pm 0.13$ & $3.24 \pm 0.15^{* *}$ & $2.26 \pm 0.09^{\$ \$}$ & $2.98 \pm 0.14 * *, \neq \neq$ \\
\hline $\mathrm{R} 5-\mathrm{R} 20\left(\mathrm{cmH}_{2} \mathrm{O} / \mathrm{L} / \mathrm{s}\right)$ & $0.43 \pm 0.07$ & $0.73 \pm 0.11 *$ & $0.56 \pm 0.07$ & $0.80 \pm 0.06 * *$ \\
\hline $\mathrm{X} 5\left(\mathrm{cmH}_{2} \mathrm{O} / \mathrm{L} / \mathrm{s}\right)$ & $-0.75 \pm 0.11$ & $-1.30 \pm 0.12 * *$ & $-0.79 \pm 0.08^{\$ \$}$ & $-1.31 \pm 0.14 * *, \pm \neq$ \\
\hline Fres $(\mathrm{Hz})$ & $10.50 \pm 0.69$ & $|4| 4 \pm 0.7 \mid. * *$ & $11.90 \pm 0.63$ & $15.48 \pm 0.77 * *, \neq \neq$ \\
\hline $\mathrm{ALX}\left(\mathrm{cmH}_{2} \mathrm{O} / \mathrm{L} / \mathrm{s} \mathrm{Hz}\right)$ & $4.16 \pm 0.90$ & $8.72 \pm 1.12 * *$ & $4.80 \pm 0.63^{\$ \$}$ & $8.99 \pm 1.20 * *, \neq \neq$ \\
\hline \multicolumn{5}{|c|}{ Differences between inspiratory and expiratory phases } \\
\hline$\Delta \mathrm{R} 5\left(\mathrm{cmH}_{2} \mathrm{O} / \mathrm{L} / \mathrm{s}\right)$ & $-0.49 \pm 0.09$ & $-0.69 \pm 0.14$ & $-0.69 \pm 0.09$ & $-0.74 \pm 0.12$ \\
\hline$\Delta \mathrm{R} 20\left(\mathrm{cmH}_{2} \mathrm{O} / \mathrm{L} / \mathrm{s}\right)$ & $-0.24 \pm 0.05$ & $-0.27 \pm 0.10$ & $-0.34 \pm 0.05$ & $-0.32 \pm 0.08$ \\
\hline$\Delta \mathrm{R} 5-\mathrm{R} 20\left(\mathrm{cmH}_{2} \mathrm{O} / \mathrm{L} / \mathrm{s}\right)$ & $-0.25 \pm 0.05$ & $-0.42 \pm 0.07$ & $-0.35 \pm 0.05$ & $-0.42 \pm 0.06$ \\
\hline$\Delta \mathrm{X} 5\left(\mathrm{cmH}_{2} \mathrm{O} / \mathrm{L} / \mathrm{s}\right)$ & $0.39 \pm 0.14$ & $1.33 \pm 0.26$ & $0.67 \pm 0.14$ & $1.61 \pm 0.35^{* *, \neq}$ \\
\hline$\Delta$ Fres $(\mathrm{Hz})$ & $-1.74 \pm 0.49$ & $-4.01 \pm 0.60$ & $-2.92 \pm 0.46$ & $-4.84 \pm 0.64 * *$ \\
\hline$\Delta \mathrm{ALX}\left(\mathrm{cmH}_{2} \mathrm{O} / \mathrm{L} / \mathrm{s} \mathrm{Hz}\right)$ & $-3.74 \pm 1.33$ & $-13.82 \pm 2.72$ & $-6.83 \pm 1.49$ & $-17.92 \pm 4.32 * *, \neq$ \\
\hline
\end{tabular}

Notes: Values are presented as the mean \pm standard error of the mean; ${ }^{* *} p<0.0$ I, ${ }^{*} p<0.05$ versus the NCT phenotype; ${ }^{\$ \$} p<0.01$, ${ }^{\$} p<0.05$ versus the AD phenotype; ${ }^{\sharp} p<0.0$ I, ${ }^{\ddagger} p<0.05$ versus the ED phenotype.

Abbreviations: NCT, normal by computed tomography; AD, airway-dominant; ED, emphysema-dominant; Fres, resonant frequency; $A L X$, low-frequency reactance area. 
Table 3 Correlation between the respiratory impedance and the degree of airway wall thickness, emphysema, and reversibility of airway obstruction in patients with COPD $(n=174)$

\begin{tabular}{|c|c|c|c|c|c|c|c|c|c|c|}
\hline & \multicolumn{2}{|c|}{ AWT-Pilo } & \multicolumn{2}{|l|}{ WA\% } & \multicolumn{2}{|l|}{ LAV\% } & \multicolumn{2}{|l|}{$\triangle$ FEV $_{1}$} & \multicolumn{2}{|c|}{ \% change in FEV } \\
\hline & $r$ & $p$-value & $r$ & $p$-value & $r$ & $p$-value & $r$ & $p$-value & $r$ & $p$-value \\
\hline \multicolumn{11}{|l|}{ Whole breath } \\
\hline R5 & 0.460 & $<0.001$ & 0.518 & $<0.001$ & 0.001 & 0.992 & 0.259 & $<0.001$ & 0.323 & $<0.001$ \\
\hline $\mathrm{R} 20$ & 0.440 & $<0.001$ & 0.484 & $<0.001$ & -0.052 & 0.496 & 0.221 & 0.003 & 0.279 & $<0.001$ \\
\hline R5-R20 & 0.283 & $<0.001$ & 0.339 & $<0.001$ & 0.083 & 0.277 & 0.200 & 0.008 & 0.262 & $<0.001$ \\
\hline$\times 5$ & -0.452 & $<0.001$ & -0.507 & $<0.001$ & -0.042 & 0.584 & $-0.25 I$ & $<0.001$ & -0.387 & $<0.001$ \\
\hline Fres & 0.430 & $<0.001$ & 0.482 & $<0.001$ & 0.195 & 0.010 & 0.208 & 0.006 & 0.340 & $<0.001$ \\
\hline$A L X$ & 0.409 & $<0.001$ & 0.469 & $<0.001$ & 0.106 & 0.167 & 0.234 & 0.002 & 0.370 & $<0.001$ \\
\hline \multicolumn{11}{|c|}{ Expiratory phase } \\
\hline R5 & $0.44 I$ & $<0.001$ & 0.478 & $<0.001$ & 0.033 & 0.667 & 0.215 & 0.004 & 0.267 & $<0.001$ \\
\hline $\mathrm{R} 20$ & 0.408 & $<0.001$ & 0.435 & $<0.001$ & -0.024 & 0.752 & 0.166 & 0.028 & 0.213 & 0.005 \\
\hline $\mathrm{R} 5-\mathrm{R} 20$ & 0.323 & $<0.001$ & 0.363 & $<0.001$ & 0.119 & 0.119 & 0.214 & 0.005 & 0.256 & $<0.001$ \\
\hline$\times 5$ & -0.431 & $<0.001$ & -0.479 & $<0.001$ & -0.079 & 0.303 & -0.226 & 0.003 & -0.359 & $<0.001$ \\
\hline Fres & 0.441 & $<0.001$ & 0.480 & $<0.001$ & 0.209 & 0.006 & 0.192 & 0.011 & 0.328 & $<0.001$ \\
\hline$A L X$ & 0.397 & $<0.001$ & 0.447 & $<0.001$ & 0.129 & 0.091 & 0.218 & 0.004 & 0.348 & $<0.001$ \\
\hline \multicolumn{11}{|c|}{ Inspiratory phase } \\
\hline R5 & 0.449 & $<0.001$ & 0.528 & $<0.001$ & -0.039 & 0.611 & 0.293 & $<0.001$ & 0.367 & $<0.001$ \\
\hline $\mathrm{R} 20$ & 0.456 & $<0.001$ & 0.517 & $<0.001$ & -0.083 & 0.278 & 0.274 & $<0.001$ & 0.343 & $<0.001$ \\
\hline R5-R20 & 0.218 & 0.004 & 0.290 & $<0.001$ & 0.052 & 0.494 & 0.183 & 0.016 & 0.228 & 0.003 \\
\hline$\times 5$ & -0.430 & $<0.00$ I & -0.493 & $<0.001$ & 0.057 & 0.453 & -0.280 & $<0.001$ & -0.397 & $<0.001$ \\
\hline Fres & 0.381 & $<0.001$ & 0.446 & $<0.001$ & 0.161 & 0.034 & 0.214 & 0.005 & 0.330 & $<0.001$ \\
\hline$A L X$ & 0.369 & $<0.001$ & 0.444 & $<0.001$ & 0.016 & 0.837 & 0.245 & 0.001 & 0.367 & $<0.001$ \\
\hline \multicolumn{11}{|c|}{ Differences between inspiratory and expiratory phases } \\
\hline$\Delta \mathrm{R} 5$ & -0.144 & 0.058 & -0.089 & 0.242 & 0.129 & 0.089 & 0.051 & 0.504 & 0.068 & 0.371 \\
\hline$\Delta \mathrm{R} 20$ & -0.057 & 0.456 & -0.001 & 0.992 & 0.105 & 0.169 & 0.148 & 0.052 & 0.174 & 0.022 \\
\hline$\Delta \mathrm{R} 5-\mathrm{R} 20$ & -0.207 & 0.006 & -0.170 & 0.025 & 0.120 & 0.116 & -0.085 & 0.267 & -0.083 & 0.275 \\
\hline$\Delta \times 5$ & 0.351 & $<0.001$ & 0.383 & $<0.001$ & -0.128 & 0.093 & 0.157 & 0.039 & 0.274 & 0.000 \\
\hline$\Delta$ Fres & -0.337 & $<0.001$ & -0.326 & $<0.001$ & 0.186 & 0.014 & -0.084 & 0.271 & -0.190 & 0.012 \\
\hline$\triangle \mathrm{ALX}$ & -0.356 & $<0.001$ & -0.387 & $<0.001$ & 0.145 & 0.057 & -0.169 & 0.026 & -0.284 & $<0.001$ \\
\hline
\end{tabular}

Note: Values are presented as the mean \pm standard error of the mean.

Abbreviations: Fres, resonant frequency; ALX, low-frequency reactance area; AWT, airway wall thickness; WA\%, percentage of wall area; LAV\%, percentage of lowattenuation volume; $\mathrm{FEV}_{1}$, forced expiratory volume in I second.

change in $\mathrm{FEV}_{1}$ ). There was no significant correlation between the FOT parameters (R5, R20, and X5) and the degree of emphysema (LAV\%).

\section{Discussion}

This is the first report to focus on the diversity of respiratory impedance according to the software-based quantification of the degree of emphysema and airway wall thickness on chest CT in patients with COPD. We showed that R5 and R20 were significantly higher in the phenotypes with airway wall thickness, that is, the $\mathrm{AD}$ and mixed phenotypes, than in the other phenotypes. Furthermore, X5 was significantly more negative, regardless of respiratory phase, in the $A D$ and mixed phenotypes than in the other phenotypes. In addition, the within-breath changes of X5 $(\Delta \mathrm{X} 5)$ were significantly greater in the mixed phenotype than in the
NCT and ED phenotypes. We also showed that these FOT parameters were significantly correlated with indices of the degree of airway wall thickness (AWT-Pi10 and WA\%) and significantly but weakly correlated with the reversibility of airway obstruction.

A previous study revealed that Rrs and Xrs parameters were significantly correlated with $\mathrm{FEV}_{1}$ and $\mathrm{FEV}_{1} / \mathrm{FVC}^{16}$ R5 is particularly frequently interpreted as a parameter of the airway caliber. ${ }^{11}$ In the present study, there were significant correlations between the FOT parameters (R5, R20, and X5) and indices of the degree of airway wall thickness (AWT-Pi10 and WA\%). However, there were no significant correlations between the FOT parameters (R5, R20, and X5) and the degree of emphysema (LAV\%). These findings suggest that the FOT parameters reflect the degree of airway disease and aid in detecting airway remodeling 


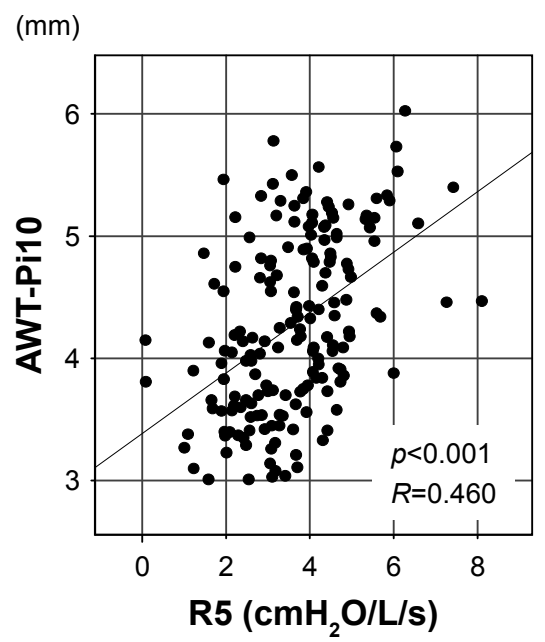

(mm)

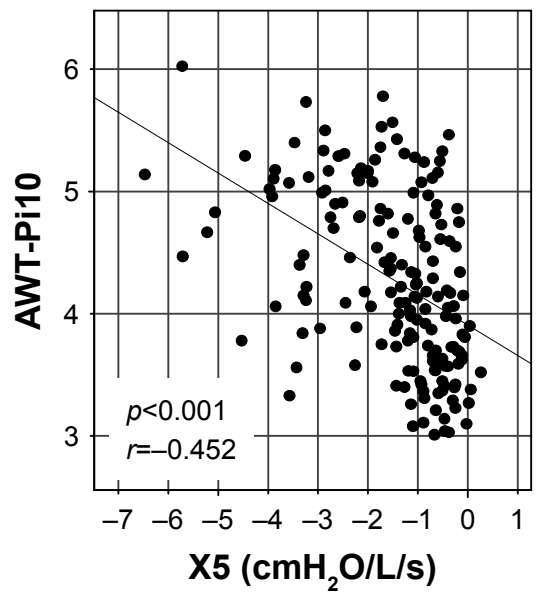

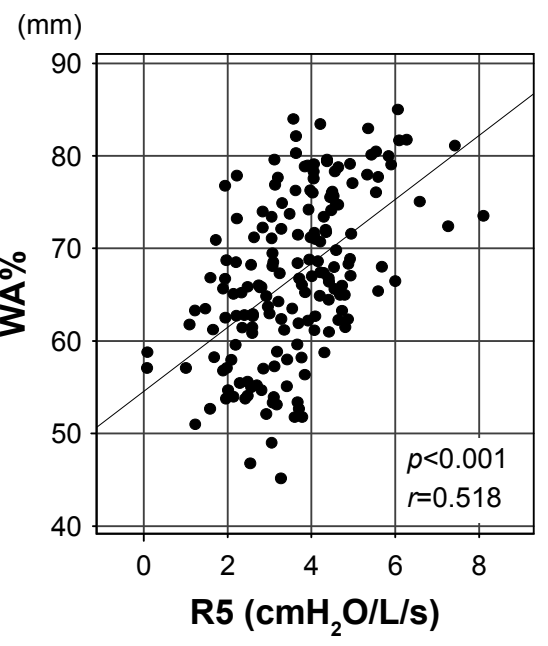

$(\mathrm{mm})$

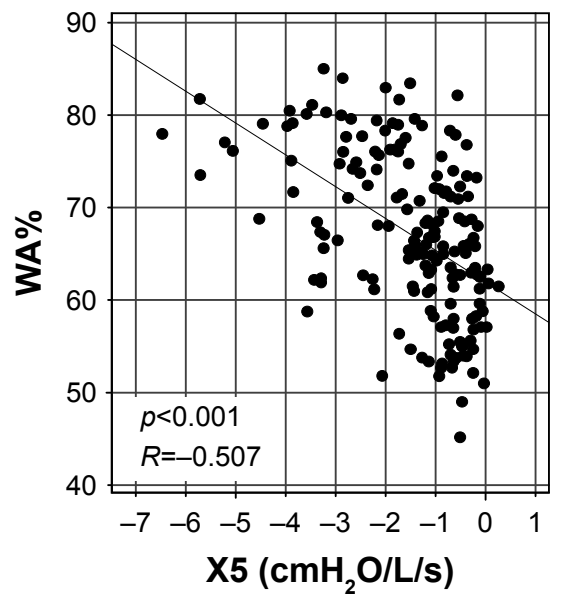

Figure 3 Correlation between respiratory impedance and the degree of airway wall thickness on chest CT in patients with COPD ( $\mathrm{n}=174)$. Abbreviations: WA\%, percentage of wall area; CT, computed tomography; AWT, airway wall thickness.

both physiologically and morphologically in patients with COPD. In addition, we found that there were significant but weak correlations between the FOT parameters (R5, R20, and X5) and the reversibility of airway obstruction. These findings suggest that the FOT parameters may predict the reversibility of airway obstruction to some extent, but not strongly. This may be because the reversibility of airway obstruction is associated not only with physiological factors due to airway obstruction but also with pharmacological factors due to susceptibility to bronchodilators, which may reflect airway remodeling.

We found that $\triangle \mathrm{X} 5$ varied among morphological phenotypes based on quantitative CT in patients with COPD. Previous studies revealed that, when airflow obstruction is present, the oscillatory signal cannot pass through the choke points to reach the alveoli, ${ }^{24}$ resulting in a marked reduction in apparent compliance; thus, X5 changes to be more physiologically negative in patients with COPD. ${ }^{25}$
$\Delta \mathrm{X} 5$ has been suggested to reflect the number and distribution of choke points within the bronchial tree, representing the overall distribution of expiratory flow limitations during tidal breathing in patients with COPD. ${ }^{15,26,27}$ Thus, $\Delta \mathrm{X} 5$ was useful for discriminating between patients with COPD and asthma. ${ }^{16,17}$ However, this approach may not be applicable to all patients with COPD due to this diversity of $\triangle \mathrm{X} 5$ among morphological phenotypes in patients with COPD.

Regarding within-breath changes in $\operatorname{Rrs}(\Delta \mathrm{R} 5, \Delta \mathrm{R} 20$, and $\Delta \mathrm{R} 5-\mathrm{R} 20)$, in the present study, there were no significant correlations between these $\Delta$ Rrs parameters and LAV\%; only $\Delta$ R5-R20 was significantly but very weakly correlated with indices of the degree of airway wall thickness (AWT-Pi10 and WA\%). In contrast, Hasegawa et al revealed that the degree of emphysema on chest CT was significantly correlated with $\Delta \mathrm{R} 5$ and $\Delta \mathrm{R} 5-\mathrm{R} 20 .{ }^{28}$ The WA $\%$ in B10 was also significantly correlated with $\Delta \mathrm{R} 5$ and $\Delta \mathrm{R} 5-\mathrm{R} 20 .{ }^{28}$ One possible reason for the differences between our present and Hasegawa et al's results 
may be differences in the patient population and methodology for evaluating the degree of airway wall thickness. The proportion of patients with the ED phenotype may have been higher in the study of Hasegawa et al than in the present study, as the percentage of low attenuation area in their study was much higher (34.3\%) and their cutoff level of low attenuation area was lower (-960 HU) than ours. ${ }^{28}$ We evaluated AWT-Pi10 and WA $\%$ by identifying and measuring all visible bronchi of the third to sixth generations which were cut in cross-section in whole lung fields for each patient, not a single bronchus.

Karayama et al revealed that the FOT parameters and $\mathrm{FEV}_{1}$ were correlated with airway luminal areas, not airway wall thickness. ${ }^{29}$ In the present study, we evaluated AWT-Pi10 and WA\%, which are the standard indices of airway wall thickness ${ }^{1,2,7,23}$ and showed that these indices were significantly correlated with the FOT parameters. One possible reason for the differences between our present study and Karayama et al's results may be differences in the methodology of evaluating the degree of airway wall thickness. We evaluated AWT-Pi10 and WA\% but did not evaluate the absolute values of airway luminal areas and airway wall thickness. In patients with COPD, airway wall area is increased with a decrease in airway luminal area; ${ }^{23}$ when patients with COPD develop airway wall thickness, their airway luminal area decreases, suggesting that high values of AWT-Pi10 and WA\% are associated with a decrease in airway luminal area in patients with COPD. Therefore, our findings are consistent with the results of Karayama et al's study, ${ }^{29}$ although the methodology was different.

A quantitative CT imaging analysis is more effective for evaluating the degree of emphysema and airway wall thickness than a visual scoring method because of the reproducibility of software-based quantification. In addition, our present and Higami et al's results show that the morphological phenotype based on quantitative $\mathrm{CT}$ is associated with the clinical characteristics and pulmonary function. ${ }^{3}$ Therefore, a quantitative CT imaging analysis is believed to be helpful in distinguishing phenotypes. Interestingly, the AD phenotype showed an increase in the Rrs and more negative values in the Xrs, suggesting severe physiological impairment, although the AD phenotype showed little emphysema on chest CT. The AD phenotype also had a better response to short-acting $\beta_{2}$ agonists. Therefore, the AD phenotype may have more clinical implications than the other phenotypes in patients with COPD. On the other hand, FOT is easy to administer because it is an effort-independent method of evaluating lung mechanics ${ }^{12,13}$ and may also reflect the degree of airway disease and the reversibility of airway obstruction in the present study, suggesting that FOT is useful for deciding on treatment with bronchodilators in clinical practice.

\section{Limitations}

There were several limitations in the present study. First, this was a single-center, uncontrolled-design retrospective study. Further prospective study is required to confirm these results. Second, generalizability is a potential problem in the present study. Shinshu University Hospital, which was the site of patient recruitment, is a major hospital and may treat greater numbers of older patients with high disease severity than other general hospitals, resulting in a potential selection bias. Third, the resolution of CT was too low to evaluate the peripheral airways more distal than sixth-generation bronchi. Major sites of airway obstruction in COPD are small airways $<2 \mathrm{~mm}$ in diameter. We evaluated third- to sixthgeneration bronchi, but more distal airways (eg, terminal bronchioles) are also important in COPD. ${ }^{29,30}$

\section{Conclusion}

There is a diversity of respiratory physiology, including the respiratory impedance and reversibility of airway obstruction, according to the software-based quantification of the degree of emphysema and airway wall thickness on chest $\mathrm{CT}$ in patients with COPD. The measurement of respiratory impedance using FOT may reflect the degree of airway disease and aid in detecting airway remodeling in patients with COPD.

\section{Disclosure}

The authors report no conflicts of interest in this work.

\section{References}

1. Johannessen A, Skorge TD, Bottai M, et al. Mortality by level of emphysema and airway wall thickness. Am J Respir Crit Care Med. 2013; 187(6):602-608.

2. Tho NV, Trang le TH, Murakami Y, et al. Airway wall area derived from 3-dimensional computed tomography analysis differs among lung lobes in male smokers. PLoS One. 2014;9(5):e98335.

3. Higami Y, Ogawa E, Ryujin Y, et al. Increased epicardial adipose tissue is associated with the airway dominant phenotype of chronic obstructive pulmonary disease. PLoS One. 2016;11(2):e0148794.

4. Kitaguchi Y, Fujimoto K, Kubo K, Honda T. Characteristics of COPD phenotypes classified according to the findings of HRCT. Respir Med. 2006;100(10):1742-1752.

5. Fujimoto K, Kitaguchi Y, Kubo K, Honda T. Clinical analysis of chronic obstructive pulmonary disease phenotypes classified using highresolution computed tomography. Respirology. 2006;11(6):731-740.

6. Grydeland TB, Dirksen A, Coxson HO, et al. Quantitative computed tomography: emphysema and airway wall thickness by sex, age and smoking. Eur Respir J. 2009;34(4):858-865.

7. Nakano Y, Wong JC, de Jong PA, et al. The prediction of small airway dimensions using computed tomography. Am J Respir Crit Care Med. 2005;171(2):142-146. 
8. Fernandes L, Fernandes Y, Mesquita AM. Quantitative computed tomography imaging in chronic obstructive pulmonary disease. Lung India. 2016;33(6):646-652.

9. Grimby G, Takishima T, Graham W, Macklem P, Mead J. Frequency dependence of flow resistance in patients with obstructive lung disease. $J$ Clin Invest. 1968;47(6):1455-1465.

10. Ohishi J, Kurosawa H, Ogawa H, Irokawa T, Hida W, Kohzuki M. Application of impulse oscillometry for within-breath analysis in patients with chronic obstructive pulmonary disease: pilot study. BMJ Open. 2011;1(2):e000184.

11. Shirai T, Kurosawa H. Clinical application of the forced oscillation technique. Intern Med. 2016;55(6):559-566.

12. Lutchen KR, Gillis H. Relationship between heterogeneous changes in airway morphometry and lung resistance and elastance. J Appl Physiol (1985). 1997;83(4):1192-1201.

13. Thorpe CW, Bates JH. Effect of stochastic heterogeneity on lung impedance during acute bronchoconstriction: a model analysis. $J \mathrm{Appl}$ Physiol (1985). 1997;82(5):1616-1625.

14. Cavalcanti JV, Lopes AJ, Jansen JM, Melo PL. Detection of changes in respiratory mechanics due to increasing degrees of airway obstruction in asthma by the forced oscillation technique. Respir Med. 2006; 100(12):2207-2219.

15. Dellaca RL, Santus P, Aliverti A, et al. Detection of expiratory flow limitation in COPD using the forced oscillation technique. Eur Respir J. 2004;23(2):232-240.

16. Mori K, Shirai T, Mikamo M, et al. Colored 3-dimensional analyses of respiratory resistance and reactance in COPD and asthma. COPD. 2011;8(6):456-463.

17. Kanda S, Fujimoto K, Komatsu Y, Yasuo M, Hanaoka M, Kubo K. Evaluation of respiratory impedance in asthma and COPD by an impulse oscillation system. Intern Med. 2010;49(1):23-30.

18. Global Initiative for Chronic Obstructive Lung Disease [homepage on the Internet]. Global Strategy for the Diagnosis, Management, and Prevention of Chronic Obstructive Pulmonary Disease. NHLBI/WHO Workshop Report. Bethesda: National Heart, Lung and Blood Institute; 2001 [Updated 2018]. Available from: http://www.goldcopd.com Accessed January 1, 2018.
19. Mori K, Shirai T, Mikamo M, et al. Respiratory mechanics measured by forced oscillation technique in combined pulmonary fibrosis and emphysema. Respir Physiol Neurobiol. 2013;185(2):235-240.

20. Shirai T, Mori K, Mikamo M, et al. Respiratory mechanics and peripheral airway inflammation and dysfunction in asthma. Clin Exp Allergy. 2013;43(5):521-526.

21. Oostveen E, MacLeod D, Lorino H, et al. ERS Task Force on Respiratory Impedance Measurements. The forced oscillation technique in clinical practice: methodology, recommendations and future developments. Eur Respir J. 2003;22(6):1026-1041.

22. Patel BD, Coxson HO, Pillai SG, et al. Airway wall thickening and emphysema show independent familial aggregation in chronic obstructive pulmonary disease. Am J Respir Crit Care Med. 2008;178(5):500-505.

23. Nakano Y, Müller NL, King GG, et al. Quantitative assessment of airway remodeling using high-resolution CT. Chest. 2002;122(6 Suppl): 271S-275S

24. Dawson SV, Elliott EA. Wave-speed limitation on expiratory flow - a unifying concept. J Appl Physiol Respir Environ Exerc Physiol. 1977;43(3):498-515.

25. O'Donnell DE, Voduc N, Fitzpatrick M, Webb KA. Effect of salmeterol on the ventilatory response to exercise in chronic obstructive pulmonary disease. Eur Respir J. 2004;24(1):86-94.

26. Dellaca RL, Rotger M, Aliverti A, Navajas D, Pedotti A, Farre R. Noninvasive detection of expiratory flow limitation in COPD patients during nasal CPAP. Eur Respir J. 2006;27(5):983-991.

27. Dellaca RL, Duffy N, Pompilio PP, et al. Expiratory flow limitation detected by forced oscillation and negative expiratory pressure. Eur Respir J. 2007;29(2):363-374.

28. Hasegawa K, Sato S, Tanimura K, et al. Emphysema and airway disease affect within-breath changes in respiratory resistance in COPD patients Respirology. 2015;20(5):775-781.

29. Karayama M, Inui N, Mori K, et al. Respiratory impedance is correlated with morphological changes in the lungs on three-dimensional CT in patients with COPD. Sci Rep. 2017;7:41709.

30. McDonough JE, Yuan R, Suzuki M, et al. Small-airway obstruction and emphysema in chronic obstructive pulmonary disease. $N$ Engl J Med. 2011;365(17):1567-1575
International Journal of COPD

\section{Publish your work in this journal}

The International Journal of COPD is an international, peer-reviewed journal of therapeutics and pharmacology focusing on concise rapid reporting of clinical studies and reviews in COPD. Special focus is given to the pathophysiological processes underlying the disease, intervention programs, patient focused education, and self management protocols.

\section{Dovepress}

This journal is indexed on PubMed Central, MedLine and CAS. The manuscript management system is completely online and includes a very quick and fair peer-review system, which is all easy to use. Visit http://www.dovepress.com/testimonials.php to read real quotes from published authors. 